\title{
Effects of Acute Organophosphate Poisoning on Glycemic Profile in Weanling Rats
}

\author{
An experimental study
}

\begin{abstract}
DANA TOMESCU1,2, CRISTIAN COBILINSCHI ${ }^{3 *}$, ALEXANDRU BAETU³, ALEXANDRA TOTAN ${ }^{1}$, PAUL TIBERIU NEAGU1,3, CAMELIA CRISTINA DIACONU1,3*, IULIA FLORENTINA TINCU ${ }^{4}$, ANCA PANTEA STOIAN ${ }^{1}$, OVIDIU GABRIEL BRATU1,5, RADU ALEXANDRU MACOVEI ${ }^{1,3}$

'University of Medicine and Pharmacy Carol Davila, 8 Eroii Sanitari Str, 050474, Bucharest, Romania

2Fundeni Clinical Institute, 258 Fundeni Road, 022328, Bucharest, Romania

${ }^{3}$ Clinical Emergency Hospital of Bucharest, 8 Calea Floreasca, 014461, Bucharest, Romania

${ }^{4}$ Grigore Alexandrescu Emergency Children Hospital, 30-32 lancu de Hunedoara Blv, 011743, Bucharest, Romania

${ }^{5}$ Emergency Central Emergency Military Hospital, 88 Mircea Vulcanescu Str, 010825, Bucharest, Romania
\end{abstract}

\begin{abstract}
Organophosphates (OP) are frequently used worldwide as pesticides in both agriculture and human households leaving toxic residues in food or living environment. OP act through acetylcholinesterase (AChE) inhibition and acute poisoning carries a higher risk of mortality due to parasympathetic overstimulation. Long-term exposure leads to nervous, hepatic or renal dysfunction. Chlorpyrifos, one of the most commonly used compound appears to cause hyperglycemia, insulin resistance and the risk of developing diabetes after prolonged exposure. The aim of this article was to assess the impact of acute OP poisoning on glycemic status in weanling mice.
\end{abstract}

Keywords: organophosphate, chlorpyrifos, cholinesterase inhibition, hyperglycemia, diabetes

Organophosphates (OPs) have become largely used in the modern world mainly for agricultural purposes in industrial areas butalso in personal households [1,2]. Wide access to pesticides has brought along the risk of acute poisoning or chronic exposure in humans, leading to an increased healthcare concern related to their toxicity [3]. The most frequent ways of poisoning are through cutaneous, respiratory or oral exposure $[4,5]$.

Moreover, the rate of suicidal actions using these hazardous compounds have imposed stricter regulations both in the United States and Europe [6].

The chemical structure of OPs is that of derivatives of phosphoric $\left(\mathrm{H}_{3} \mathrm{PO}\right)$, phosphorous $\left(\mathrm{H}_{3} \mathrm{PO}_{3}\right)$ or phosphinic acid $\left(\mathrm{H}_{3} \mathrm{PO}_{2}\right)\left[{ }^{3}\right]$ and act through acetylcholine inhibition that results in its accumulation at the neuromuscular junction followed by an overstimulation of nicotinic and muscarinic receptors $[8,9]$.

Chlorpyrifos is one of the most commonly utilized OP with neurological, respiratory and renal impairment [10]. Apart from these, it appears that exposure to OP can lead to metabolic disbalance including hyperglycemia, insulin resistance and the risk of developing diabetes [11]. The metabolite of chlorpyrifos, chlorpyrifos-oxon, is formed in the liver under the action of cytochrome P450 and is responsible for the anti-cholinergic effect [12]. Consequently, paraoxonase inactivates it to diethyl hiophosphoric acid [13].

The objective of the present study was to evaluate the impact of acute OP poisoning on glycemic profile in weanling mice.

\section{Experimental Part \\ Study design}

We conducted a prospective, experimental study on weanling Wistar rats from a certified laboratory. The study duration was of three months, from February to April 2017. In order to minimize gender and hormonal bias, we only included male rats that were subjected to chlorpyrifos exposure. Subsequent blood draw was performed as detailed in the following section. The study received approval from the designated Ethics' Committee after thoroughly revising the study protocol.

\section{Materials and methods}

The study included eight Wister rats of the same age, gender and weight that had food and water available ad libitum prior to testing. They were fed with certified rats chow (delivered from the laboratory) and tap water and kept at room temperature with 12 hours artificial light per day.

They were first tested for baseline levels of glycaemia, insulin and insulin-like growth factor-1 (IGF-1). Secondly, $0.1 \mathrm{mg} / \mathrm{kg}$ chlorpyrifos was administered by oral gavage in order to induce acetyl-cholinesterase inhibition. New blood samples were taken to determine the level of cholinesterase and the above mentioned parameters of the glycemic profile. Venous blood samples were drawn in fasting rats two hours after OP poisoning, incising the end point of the tail where a drop of blood was obtained. Glucose concentrations were detected using the Biosystems analyzer and expressed as mg/dl. Cholinesterase levels were identified using the spectrophotometric method while the other tests of interest, hormone level detection were determined using ELISA kits for rats (IGF-1 ELISA kit ABIN3032869, Insulin ELISA kit ABIN1116659), using the ELISA sandwich technique for quantitative detection. Blood sample procedures and organophosphate administration were performed under general anesthesia with isoflurane $1 \%$ and ketamine $40 \mathrm{mg} / \mathrm{kg} / \mathrm{xylazine} 5 \mathrm{mg} / \mathrm{kg}$, according to The Institutional Animal Care and Use Committee ( IACUC) Guidelines.

\section{Statistical analysis}

The statistical analysis was performed using the SPSS statistical software, version 20.0, setting a standardized significant $P$ value at 0.05 . Data was expressed as mean 
value \pm standard deviation (SD). Differences between groups were recorded with the aid of Student t-test, whereas Spearman and Pearson tests were used for correlations.

We calculated the area under the curve (AUC) for indices of disease activity. Values superior to 0.90 stand for high accuracy, from 0.70 to 0.90 for moderate accuracy, and from 0.50 to 0.70 for poor accuracy.

\section{Results and discussions}

All eight rats included in the study were available for both blood determinations, atbaseline and two hours post exposure.

Levels of cholinesterase were significantly decreased after exposure to chlorpyrifos, having a baseline mean value of $1471.6 \pm 389.79$ compared to $12.75 \pm 7.36 \mathrm{u} / \mathrm{L}$ after poisoning $(p<0.001)$. Figure 1 emphasizes the difference of serum cholinesterase after organophosphate exposure and before pesticide administration, thus confirming the state of acute intoxication.

These values are of high significance since they appear to have a high coefficient of variation, of $142.5 \%$.

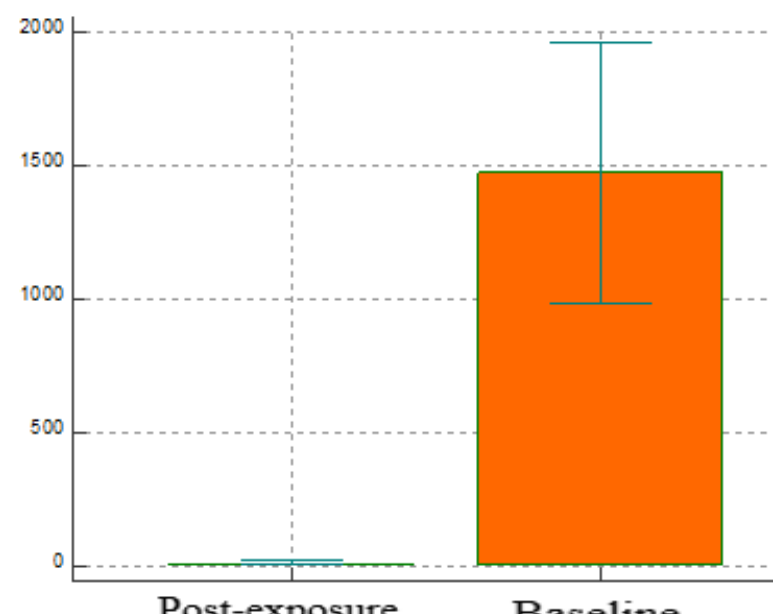

Fig.1. Cholinesterase levels at baseline and post-exposure

Blood sugar levels were significantly increased in rats after OP administration, with a mean value of $117 \mathrm{mg} / \mathrm{dL}$ versus $103 \mathrm{mg} / \mathrm{dL}$ previous to poisoning, with a $\mathrm{p}$ of 0.015 (fig. 2). The coefficient of variation was $12.06 \%$.

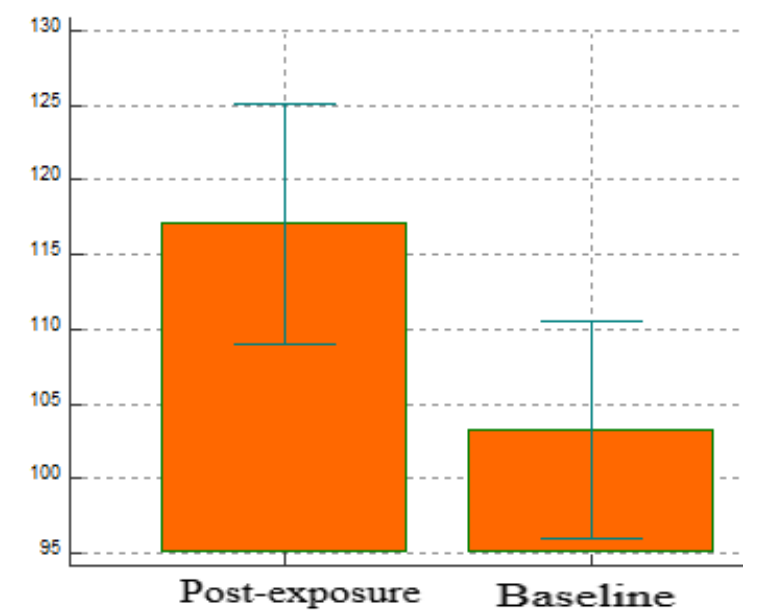

Fig. 2. Blood glucose concentrations post-exposure and at baseline

In accordance with higher glycemia levels after poisoning, the insulin levels were higher at this moment, with a mean value of $24.62 \pm 6.45$ compared to $14.2 \pm 2.58$ at baseline ( $p$ 0.006). Values of interest are detailed in the table below (fig. 3). The coefficient of variation was $47.1 \%$ for this determination.

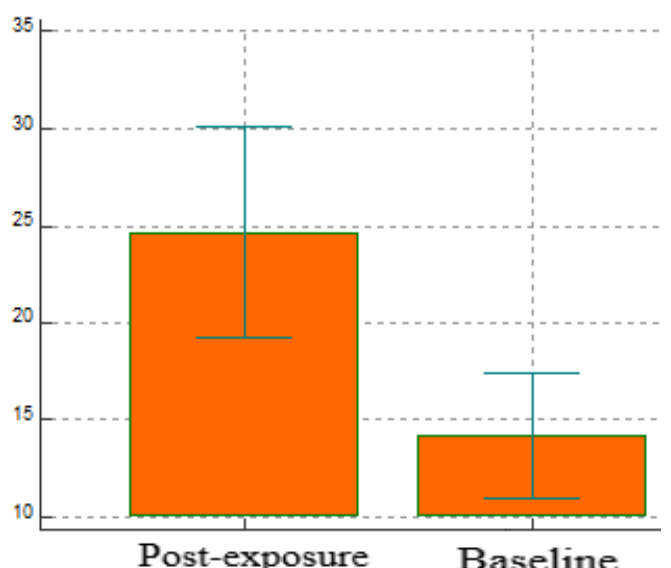

Fig. 3. Insulin levels post-exposure and at baseline

Insulin-like growth factor (IGF) -1 levels were also determined before and after OP exposure and the values were as expected higher after poisoning compared to baseline levels, $251 \pm 17.8$ versus $211 \pm 19.57$, respectively $(p=0.0029)$, with a lower coefficient of variation of $15 \%$ (fig. 4). The later may indicate that one of the samples strongly influenced the value of IGF-1.

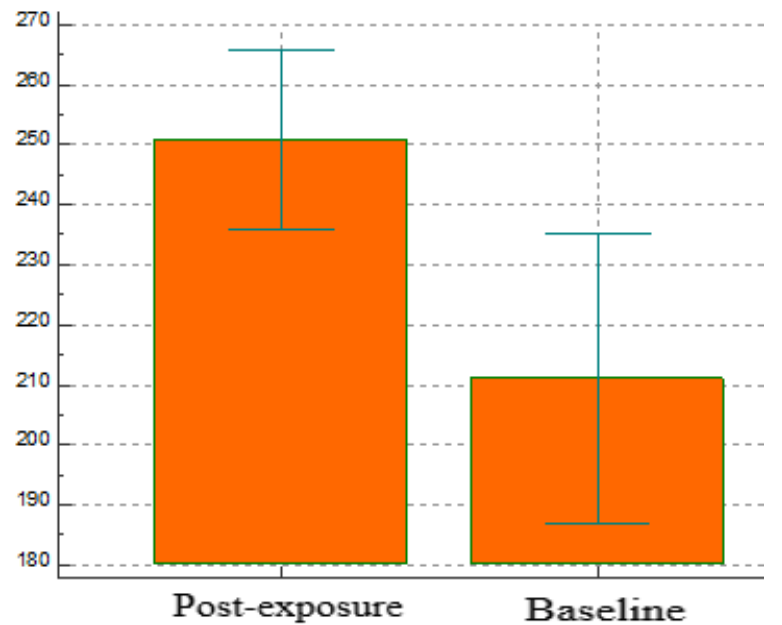

Fig. 4. Insulin-like growth factor (IGF) -1 levels at baseline and post-exposure

Using ROC curves and the area under the curve (AUC) we measured how well the studied parameters can differentiate between the baseline moment and after OP poisoning. Therefore we expressed the sensitivity (Se) and specificity (Sp) of each variable, knowing they can prove helpful in establishing a positive diagnosis and risk evaluation in the long term follow-up of patients.

Using cholinesterase as a confirmation marker of OP exposure, a cut-off under $28 \mathrm{U} / \mathrm{L}$ is highly indicative of this status, having a Se and Sp of $100 \%$ and an AUC of 1 (fig. 5).

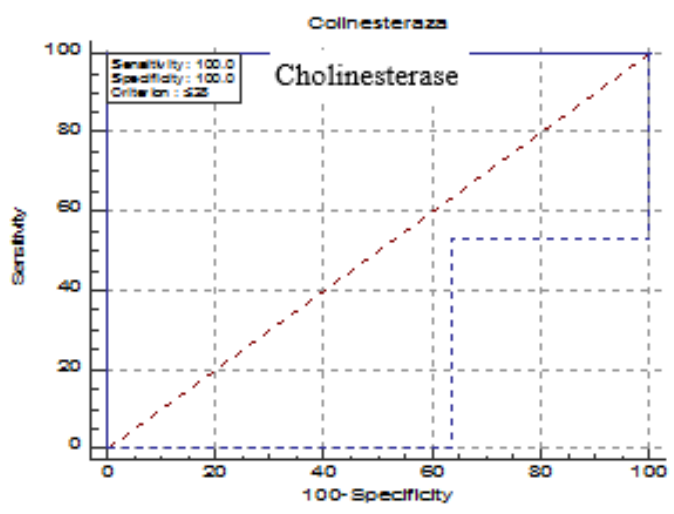

Fig. 5. ROC curve for cholinesterase levels 
A glycemic level of $111 \mathrm{mg} / \mathrm{dL}$ has a Se of $75 \%$ and a Sp of $100 \%$, therefore a value below $111 \mathrm{mg} / \mathrm{dl}$ indicates a low probability of OP poisoning, among other clinical and biological indicators (fig. 6). The AUC for this parameter was satisfactory, of 0.86 .

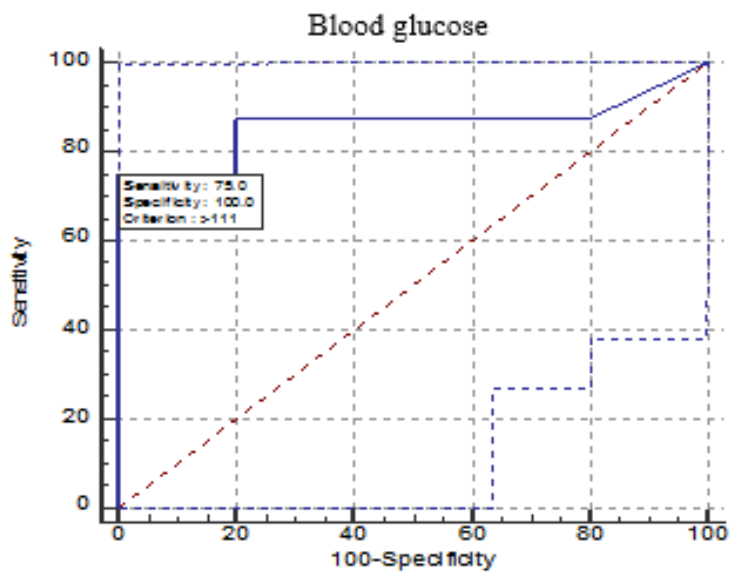

Fig. 6. ROC curve for cholinesterase levels

Regarding IGF-1, using it as the sole indicator of poisoning, statistical analysis shows that if a cut-off of 239 is not reached (Sp 100\%, Se $85 \%$ ), the poisoning is unprobable (fig. 7). Likewise, an insulin level over 18 units is suggestive of intoxication (fig. 8).

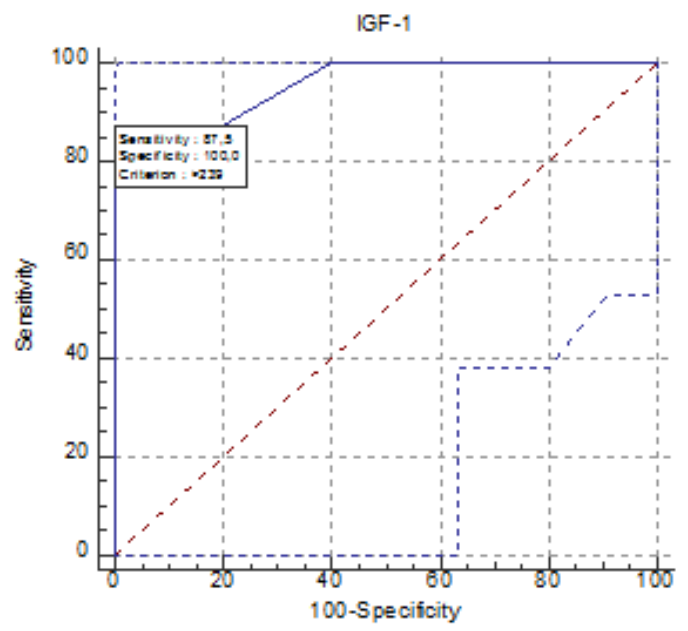

Fig. 7. ROC curve for IGF-1 levels

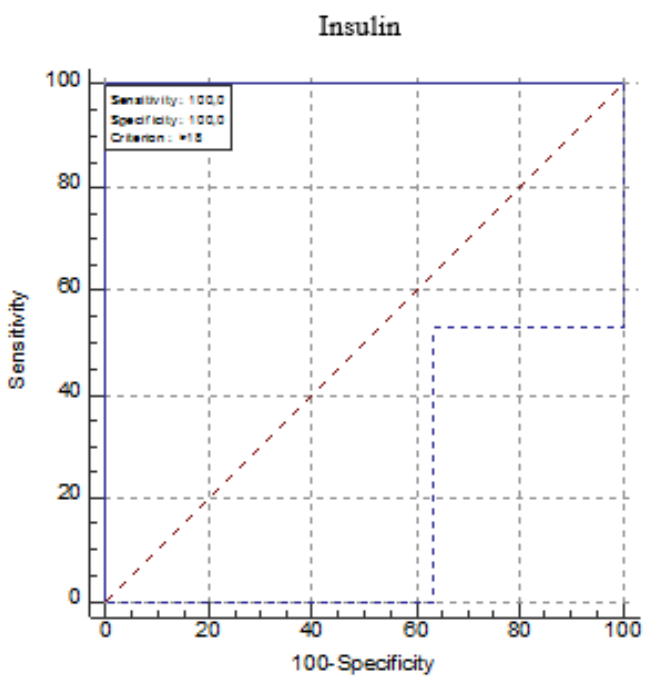

Fig. 8. ROC curve for insulin levels

Apart from neurological toxicity and oxidative stress, studies on rats have previously shown that OPs, including chlorpyrifos, can induce hyperglycemia and further diabetes [14]. These metabolic alterations can be partly explained by an impaired insulin stimulated glucose uptake that can be due to cell lysis or OP toxicity on cellular metabolism [15].

A brief case report article in 1981 detailed two cases admitted after OP exposure and who exhibited hyperglycemia [16]. Glucose serum levels were rapidly lowered after pralidoxime administration, proving the link between poisoning and hyperglycemia [16].

A literature review in 2007 on altered glucose homeostasis induced by OP exposure suggested specific features of glycemic levels depending on the type of pesticide [17]. For example, a single dose of chlorpyrifos induces a rapid increase in blood glucose followed by a normalization trend. Most of the OP products modify glucose levels in a reversible manner. This subsequent normalization might be due to increased glycogen deposits in the liver, incriminating the gluconeogenesis process as main mechanism[18].Moreover, the fact that cholinesterase levels increase while glycemic levels normalize suggest that acethylcolinesterase inhibition may play a role in this metabolic disturbance [19].

Chronic OP exposure was associated with both glycogenolytic and gluconeogenic processes [20,21]. A recent prospective study in 2015 aimed to assess the glycemic status in OP poisoned patients. It included 102 patients with history of OP exposure and confirmed hyperglycemia and glycosuria, suggesting that glycemic parameters correlate to the severity of poisoning at the time of admission [22].

A study published in 2018 suggested a higher occurrence of diabetes among Thai farmers exposed to pesticides, while another indicated that OP toxicity interferes with insulin secretion by damaging mitochondria cells [23].

A study published din 2011 evaluated serum glucose concentrations after co-administration of chlorpyrifos and lead, as they are considered the two mostly spread environmental threats. A high glucose level was noticed in this group, and authors suggested it might be due to pancreatic lipoperoxidation, which ultimately affects insulin synthesis, the essential hormone that regulates glucose concentration in the blood [24].

Moreover, intense muscular activity resulting from increased cholinergic activity and pancreatitis due to cholinergic stimulations have been shown to raise glucose levels [24].

IGF-1, also known as somatomedin C, belongs to a family of peptides that are partially dependent on growth hormone (GH) secretion. IGF-1 is involved in anabolic and mitogenic processes mediated by GH [25]. Furthermore, IGF-1 is acts as an acute phase response to stress, thus explaining increased values post OP exposure $[16,26]$.

\section{Conclusions}

The present study shows significant alterations in glycemic profile in weanling rats after acute OP exposure. Pesticide poisoning, confirmed by low cholinesterase levels, led to hyperglycemia and an increase in both insulin and insulin-like grow th factor-1 in young rats.

To our knowledge, the current research work is the first one to be published on the effect of chlorpyrifos on blood glucose in weanling rats. The obtained results are well supported by previous findings from epidemiological studies and other animal study with adult rats.

Given the scarcity of data on this topic, we suggest that more studies should be made, with a larger sample size and a long-term follow up. In addition, practical measures by authorities to control these harmful pesticides are needed. 


\section{References}

1.LIEBERMAN, A.D., CRAVEN, M.R., LEWIS, H.A., NEMENZO, J.H., J. Occup. Environ. Med., 11, no. 40, 1998, pp. 954-957.

2.GUPTA, R.C., MALIK, J.K., MILATOVIC, D., Reproductive and Developmental Toxicology, 2011, pp. 471-486.

3.J AGA K., DHARMANI, C., Rev. Panam. Salud Pública, 3, vol. 14, 2003, pp. 171-185.

4.GUPTA, R., Toxicology of Organophosphate \& Carbamate Compounds. 2006.

5.RODNITZKY, R.L., LEVIN, H.S., MICK, D.L., Arch. Environ. Heal. An Int. J., 2 vol. 30, 1975, pp. 98-103.

6.KAZEMI, M., Agric. Sci. Res. Journals, 9, vol. 2, 2012, pp. 512-522.

7.KWONG, T.C., Therapeutic Drug Monitoring, 1, vol. 24, 2002, pp. 144-149.

8.NARAHASHI, T., Toxicology of Organophosphate $\&$ Carbamate Compounds, 2006, pp. 339-345.

9.COHEN, S.D., EHRICH, M., Toxicol. Appl. Pharmacol., 1, vol. 37, 1976, pp. 39-48.

10.COBILINSCHI, C., TINCU, R., TOTAN, A., GHIORGHIU, Z., NEAGU, P., MACOVEI, R., Toxicol. Lett., 169, 2017, p. 473.

11.SLOTKIN, T.A., BROWN, K.K., SEIDLER, F.J ., Environ. Health Perspect., 10, vol. 113, 2005, pp. 1291-1294.

12.BRZAK, K.A., HARMS, D.W., BARTELS, M.J ., NOLAN, R.J ., J. Anal. Toxicol., 3, vol. 22, 1998, pp. 203-210.

13.COSTA, L.G., COLE, T.B., JANSEN, K.L., FURLONG, C.E., Paraoxonase and organophosphate toxicity, 2008, pp. 209-220.
14.FANG, B., LI J.W., ZHANG, M., REN F.Z., PANG, G.F., Food Chem. Toxicol., vol. 111, 2018, pp. 144-152.

15.LUKASZEWICZ-HUSSAIN, A., Med. Pr., 4, vol. 64, 2013, pp. 527-31. 16.J OSHI, A.K.R., RAJINI, P.S., Organophosphorus Insecticides and Glucose Homeostasis, 2003, pp. 63-84.

17.LASRAM M.M., ANNABI AB, REZG R, Pestic. Biochem. Physiol., 3, vol. 92, 2008, pp. 114-119.

18.SHRIJ ANA, S., SINGH, V., SHANMUGASUNDARAM, B., SARKAR, S.K., JeEVARATNAM, K., KONER, B.C., J. Drug Metab. Toxicol., 3, vol. 7, 2016.

19.SULTATOS, L.G., Toxicology of Organophosphate $\&$ Carbamate Compounds, 2006, pp. 209-218.

20.MOSTAFALOU, S., EGHBAL, M.A., NILI-AHMADABADI, A., BAEERI, M., ABDOLLAHI, M., Toxicol. Ind. Health, 9, vol. 28, 2012, pp. 840-851. 21. DASCALU, C.G., CARAUSU, E.M., MANUC, D., Proceedings of World Academy of Science, Engineering and Technology, vol. 28, 2008, p. 278.

22.PANDA, S., NANDA, R., MANGARAJ, M., RATHOD, P.K., MISHRA, P.K., J. Nepal Health Res. Counc., 31, vol. 13, 2015, pp. 214-219.

23.J UNTARAWIJIT, C., JUNTARAWIJIT, Y., Environ. Health Prev. Med., 11, vol. 23, 2018.

24.AMBALI, S.F., SHUAIB, K., EDEH, R., ORIEJI, B.C., SHITTU, M., AKANDE, M., Biol. Med., 13, vol. 3, 2011, pp. 6-14.

25.DUTTA, P., KAMATH, S., BHALLA, A., Indian J. Endocrinol. Metab., 179, vol. 19, 2015, p. 116.

26. MAZILU, L., NICULESCU, Z., SUCEVEANU, A.I., Revista Romana de Bioetica, 3, vol. 8, 2010, pp. 181-188.

Manuscript received: 23.08 .2018 